\title{
Doğumsal nazolakrimal kanal tıkanıklığı tedavisinde sondalama yönteminin etkinliği ve zamanlamasının başarıya etkisi
}

\section{The effectiveness and timing effect of probing in the treatment of congenital nasolacrimal channel occlusion}

\author{
Müslüm Toptan' \\ ${ }^{1}$ Harran Üniversitesi Tıp Fakültesi, Göz Hastalıkları AD. Şanlıurfa/Türkiye
}

\section{Öz.}

Amaç: Doğumsal nazolakrimal kanal tıkanıklığı (DNLKT) olan hastalarda sondalama yönteminin etkinliğini ve yaş gruplarına göre başarı oranlarını değerlendirmek.

Materyal ve Metot: Bu çalışmada, DNLKT nedeni ile 2016-2019 yılları arasında sondalama işlemi uygulanan hastaların kayıtları retrospektif olarak incelendi. Hastaların sondalama yapıldığı zamandaki yaşı, işlem sonrası epifora varlığı, sulanma yakınmalarının durumu ve floresein kaybolma testinin sonuçları not edildi. Ameliyat sonrası dönemde işlemin başarısı yaş gruplarına göre değerlendirildi.

Bulgular: DNLKT tanısı alan 45 kız (\%58.5), 32 erkek (\%41.5) toplam 77 hasta çalışmaya alındı. Olguların yaş ortalaması $18.8 \pm 10.4$ ay (2-39 ay) ve ortalama takip süresi $11.6 \pm 7.6$ ay (6-18 ay) idi. Hastaların 35 ' inde sağ (\%37.2), 42' sinde sol (\%44.7), 17 ' inde her iki gözüne (\%22.1), toplam 94 göze sondalama uygulandı. Hastalar başvuru esnasındaki yaşlarına göre dört farklı gruba ayrıldı. Birinci grupta (0-12 aylık) sondalama ile \%100, ikinci grupta (13-24 aylık) 1. sonda uygulaması ile \%90.0, 2. sondalama ile \%97.4 oranında başarı sağlandı. Üçüncü grupta (25-36 ay) sondalama ile \%66.7 oranında başarıyla uygulandı. Dördüncü grupta (37-48 ay arası) sondalama tedavisi ile \% 56.2 oranında başarı elde edildi.

Sonuç: Hidrostatik masaj tedavisi ile düzelmeyen DNLKT olguları için sondalama işlemi erken yaş gruplarında etkili bir tedavi şeklidir. Hastanın yaşı artııça başarı şansı azalacağı için sondalama uygulamasında geç kalınmaması gerekmektedir.

Anahtar kelimeler: Doğumsal, Nazolakrimal kanal, Epifora, Sondalama

Abstract

Background: To evaluate the efficacy of probing therapy and the success rates according to age groups in patients with congenital nasolacrimal duct obstruction (CNCO).

Methods: In this study, the records of patients who underwent probing between 2016-2019 due to CNCO were examined retrospectively. The age of the patients at the time of probing, the status of complaints of posttreatment irrigations, the presence of epiphora, and the results of the fluorescein disappearance test were noted. The success of the procedure was evaluated according to the age groups.

Results: A total of 77 patients (45 female (58.5\%) and 32 men (41.5\%) with congenital nasolacrimal duct obstruction were included in the study. The mean age of the patients was 18.8 \pm 10.4 months (2-39 months) and the mean follow-up period was $11.6 \pm 7.6$ months (6-18 months). In 35 patients, right (37.2\%), in $42(44.7 \%)$ left and in $17(22.1 \%)$ both eyes were probed in 94 eyes. The patients were divided into four groups according to their age. In the first group (0-12 months), the success rate was 100\% with the probing, in the second group (13-24 months) by $90.0 \%$ with the first probe application and in the second by $97.4 \%$. In the third group (25-36 months), $66.7 \%$ was successfully applied by probing. In the fourth group (37-48 months), the success rate was $56.2 \%$.

Conclusions: Probing for CNCO patients not recovering with hydrostatic massage treatment is an effective treatment method in early age groups. The patient should not be late in probing because the chances of success will decrease as the patient's age increases.

Key words: Congenital, Nasolacrimal duct, Epiphora, Probing

\section{Sorumlu Yazar I Corresponding Author}

Dr. Müslüm TOPTAN

Harran Üniversitesi Tıp Fakültesi

Göz Hastalıkları AD.,

Osmanbey Kampüsü

Şanlıurfa / TÜRKIYE

Tel: 04143444444

e-mail: muslum.toptan@hotmail.com.tr

Geliş tarihi / Received: 22.03.2019

Kabul tarihi / Accepted: 23.05.2019

DOI: 10.35440/hutfd.543361 


\section{Giriş}

Doğumsal nazolakrimal kanal tıkanıklı̆ı (DNLKT) doğum sonrası birkaç hafta içerisinde gözde yaşarma, ara ara çapaklanma şikayeti ile gelen ve kese bölgesine basıldığında mukoid salgı reflüsü, göz yaşı göllenmesi ve konjonktivit ataklarına neden olabilen klinik bir durumdur (1). DNLKT en sık görülen lakrimal sistem anomalisi olup, yenidoğan ve infantlarda epiforanın en yaygın sebebidir. Nazolakrimal kanalın alt ucunda bulunan Hasner valvi denilen açıklığın doğuma kadar kanalize olmamasından kaynaklandığı ve membranöz olan bu tıkanıklığın olguların \%70' inde ilk 3 ay içinde, \%95' inde ilk yıl içinde spontan açıldığı bildirilmiş̧ir $(2,3)$.

Nazolakrimal pasajın spontan açımadığı durumlarda hidrostatik basıncı artıracak şekilde yapılacak masajın, kanal ucundaki membranı rüptüre ederek tıkanıklığın açılmasına katkıda bulunduğu gösterilmiştir (4). Ancak tedaviye yanıt vermeyen hastalarda 1 yaşından sonra sondalama işlemine geçilmesi gerekmektedir (5). Sondalamanın amacı nazolakrimal kanalın alt ucuna ulaşmak ve membranı delip açarak sıvı geçişini sağlamaktır. Başarısızlık durumunda aynı işlem birkaç kez daha yinelenebilir (6).

Ayrıca sık enfeksiyon geçiren hastalarda veya mukosel varlığında sondalama 1 yaşından önce yapılmalıdır. Daha geç dönemde yapılan sondalama sonucunda lakrimal apse, akut selülit, dakriyosistit gibi komplikasyonların görülebileceği bildirilmiştir (7). Hidrostatik masaj ile kendiliğinden düzelme olmayan hastalarda inflamasyon sonucunda oluşan skar ve fibrotik değişikliklerin sondalamanın başarısını düşürdüğü kabul edilir (8). Bu nedenle hastanın yaşı ilerledikçe başarı şansı azalacağından sondalama uygulamasında geç kalınmaması gerekmektedir. 1 yaş altında hidrostatik masaj ile diğer girişimsel tedavilerin tam olarak ne zaman uygulanması konusunda ve 3 yaş üzerinde sondalamanın başarısı üzerine tam bir fikir birliği halen mevcut değildir.

Biz de bu çalışmada kliniğimize başvurmuş DNLKT hastalarını çeşitli yaş gruplarına ayırarak uyguladığımız sondalama tedavisinin sonuçlarını karşılaştırmayı amaçladık.

\section{Materyal ve Metot}

Bu çalışmada 2017-2019 yılları arasında yenidoğan ile 4 yaş arasında gözde sulanma, ara ara çapaklanma şikâyeti ile kliniğimize başvuran, alınan öykü ve klinik muayene sonucu DNLKT tanısı alan, hidrostatik masaj tedavisi verilen ancak geçmeyen, sondalama işlemi uygulanan hastaların kayıtları retrospektif olarak incelendi.

Tüm hastaların alt konkonktival forniksine \%2' lik fluoresein damla damlatılarak floresein kaybolma testi yapıldı. Beş dakika geçmesine rağmen, boyanın gözyaşı havuzundan temizlenmemiş olması tıkanıklık lehine değerlendirildi. İslem öncesi hastaların tam oftalmolojik muayeneleri yapıldı. Medikal ve cerrahi öyküleri sorgulandı.
Hastalar kliniğimize başvurma yaşlarına göre dört gruba ayrıldı. Birinci gruba yaşları 0-12 ay arasında değişen, ortalama yaşları 9.6 ay olan 6' sı kı, 5' i erkek toplam 11 hastanın 15 gözü, ikinci gruba yaşları 13-24 ay arasında değişen, ortalama yaşları 18.3 ay olan 19' u kı, 11' i erkek toplam 30 hastanın 39 gözü, üçüncü gruba yaşları 25-36 ay arasında değişen, yaş ortalamaları 27.2 ay olan 12' si kız, 10' u erkek toplam 22 hastanın 24 gözü, dördüncü gruba yaşları 37-48 ay arasında değişen, yaş ortalamaları 38.3 ay olan $8^{\prime}$ i kız, 6' । erkek toplam 14 hastanın 16 gözü dahil edildi.

Birinci gruptaki hastalar nazolakrimal kese bölgesine hidrostatik masaj yapılması önerilen ancak masaj yapılmasına rağmen sık enfeksiyon geçiren, mukoseli olan hastalardan, diğer gruplar 1 yaşın üstünde masaj yapılmasına rağmen pasajı kapalı olan hastalardan oluşturuldu. Daha önce sondalama yapılmış, nazolakrimal sistem travma öyküsü olan, akut dakriosistit, dakriokutanoz fistül, kanaliküler veya punktal anomalisi olan hastalar çalışmaya alınmadı.

Işlem inhalasyon anestezisi altında ameliyathane şartlarında gerçekleştirildi. Sondalama işlemi esnasında üst-alt punktumlar dilate edildi, baticon ile sulandırılmış serum fizyolojik punktumdan verilerek sıvının diğer punktumdan geri geldiği görülüp tanı kesinleştirildikten sonra sondalama işlemine başlandı. Sondalama alt kanalikülü travmatize etmemek için üst kanalikülden yapıldı. Bowman sonda ile punktumdan kanaliküle girilip yatay konumda ilerletilerek, lakrimal kemiğin nazal duvarına kadar devam edildi. Bu sırada kanalikülde katlantı olmaması için üst kapak dışarıya doğru çekildi. Kemiğe dayandıktan sonra sonda yaklaşık $1 \mathrm{~mm}$ geri çekilip, 90 derece aşağı yöneltilerek alt kısımdaki nazolakrimal kanala doğru ilerletildi. Membran rüptürü hissedilip kanalın alt ucundan geçtikten ve burundan sokulan metal ile temas sağlandıktan sonra sonda geri çekilip betadin ile sulandırılan sıvı kanalikülden verildi. Bu esnada alt meatusa aspiratör konularak pasajın açıklığı kontrol edildi. Çift taraflı tıkanıklığı olan olgularda işlem aynı seans esnasında uygulandı. Ameliyat sonrası 1 hafta tobramisin damla $(5 \times 1)$ ve florometalon damla $(5 \times 1)$ verildi. Kontrollerde ailelere sulanma şikayetlerinin devam edip etmediği soruldu. Fluoresein kaybolma testi yapıldı. Sulanma şikayetlerinin olmaması, muayenede epifora izlenmemesi ve floresein kaybolma testinde boya göllenmemesi durumu sondalamanın başarılı olması olarak kabul edildi. İlk sondalamaya rağmen, tıkanıkıı̆ın açılmadığı 2 yaş altındaki olgulara yaklaşık 2 ay arayla 2 . sondalama işlemi yinelendi, 2 yaş üstündeki olgulara ise silikon tüp entübasyonu uygulandı.

\section{Bulgular}

DNLKT tanısı alan ve kliniğimizde bir kez sondalama işlemi yapılan 77 hastanın 94 gözü çalışmaya alındı. Hastaların cinsiyet dağılımı 45 kız $(\% 58,5), 32$ erkek 
$(\% 41,5)$ şeklinde ve yaş ortalaması da $18.8 \pm 10,4$ ay $(2-$ 39 ay) idi. Ortalama takip süresi $11.6 \pm 7,6$ ay (6-18 ay) olarak bulundu. Hastaların 35 ' inde sağ $(\% 37,2), 42$ ' sinde sol $(\% 44,7), 17$ ' sinde her iki gözüne $(\% 22,1)$ sondalama uygulandı. Tüm yaş gruplarında ilk sondalama ile 94 gözün 75 ' inde $(\% 83,0)$ başarı sağlandı. Hastaların yaş gruplarına göre uygulanan sonlama işleminin sonuçları, hastaların demografik özellikleri Tablo 1' de özetlenmiştir. Birinci gruptaki $11(\% 14,2)$ hastadan 8' i sık enfeksiyon geçiren, 3' ü mukoseli olan hastalar olup uygulanan sondalama sonucunda tümünde şikâyetlerin düzeldiği gözlendi.

İkinci gruptaki $30(\% 38,9)$ hastanın 39 gözüne sondalama işlemi uygulandı ve 26 hastanın 35 (\%90.0) gözünde şikâyetler tamamen düzeldi. Şikâyetleri düzelmeyen 4 hastaya yaklaşık 2 ay sonra ikinci bir sondalama işlemi uygulandı. İkinci sonda uygulaması sonrası 3 hastanın 3 $(\% 7,0)$ gözünde şikayetlerinde düzelme oldu ve ikinci sondalama ile \%97,4 oranında başarı sağlandı. İkinci sonda uygulaması ile de şikâyetleri düzelmeyen $1(\% 3,0)$ hasta silikon tüp uygulaması ile tedavi edildi.

Üçüncü gruptaki $22(\% 28,5)$ hastanın 24 gözüne sondalama işlemi uygulandı. Sondalama sonrası 14 hastanın 16 $(\% 66,7)$ gözünde şikâyetleri düzeldi. Kalan $8(\% 33,3)$ hastaya silikon tüp entübasyonu yapıldı.

Dördüncü gruptaki hastalara da sondalama işlemi uygulandı. Bu grupta sondalama sonrası 7 hastanın $9(\% 56,2)$ gözünde hastanın şikayetleri düzeldi. Kalan 7 hastaya $(\% 43,7)$ silikon tüp entübasyonu uygulandı. Hastaların yaş gruplarına göre başarı ile sonuçlanan gözlerdeki işlem sayıları Tablo 2' de gösterilmiş̧ir.

Tablo 1. Hastaların yaş gruplarına göre uygulanan tedavi yöntemleri, sonuçları, hastaların demografik özellikleri

\begin{tabular}{ccccc} 
Yaş grubu & Yaş ortalaması(ay) & Hasta/Göz sayısı $(\mathbf{n})$ & Cinsiyet(K/E) & Başarı oranı (\%) \\
\hline $\mathbf{0 - 1 2}$ ay arası & 9.6 & $11 / 15$ & $6 / 5$ & 100 \\
13-24 ay arası & 18.3 & $30 / 39$ & $19 / 11$ & 90.0 \\
$\mathbf{2 5 - 3 6}$ ay arası & 27.2 & $22 / 24$ & $12 / 10$ & 66.7 \\
$\mathbf{3 7 - 4 8}$ ay arası & 38.3 & $14 / 16$ & $8 / 6$ & 56.2 \\
\hline
\end{tabular}

Tablo 2. Yaş gruplarına göre başarı ile sonuçlanmış gözlere uygulanan işlemler

\begin{tabular}{ccccc}
\hline Yaş grubu & Göz sayısı & 1. işlem & 2 işlem & 3. işlem \\
\hline 0-12 ay arası & 15 & 15 göz sondalama & \\
13-24 ay arası & 39 & 35 göz sondalama & 3 göz sondalama & 1 göz silikon entübasyonu \\
25-36 ay arası & 24 & 16 göz sondalama & 8 göz silikon entübasyonu & \\
37-48 ay arası & 16 & 9 göz sondalama & 7 göz silikon entübasyonu & \\
\hline
\end{tabular}

\section{Tartışma}

Çocukluk yaş gurubunda görülen epiforanın en sık nedeni DNLKT olup, tıkanıklık nedeni en sık olarak Hasner valvülü civarında gelişen membran gösterilmektedir $(2,3)$. Bu olguların büyük kısmında kanalın 1 yaşına kadar hidrostatik masajın da katkısıyla açılması beklenmektedir (4). Ancak yanıt alınamayan olgularda ilk tercih edilen yöntem sondalama uygulamasıdır (5). Ayrıca mukoseli olan bebeklerde hidrostatik masajın faydası olmayacağından, sık enfeksiyon atağı geçiren bebeklerde sellülit, abse, dakriosistit gibi ileri komplikasyonların önüne geçmek için 1 yaş altında sondalama uygulamaktayız.

Çalışmamızda tüm yaş gruplarında ilk sondalama ile ortalama $\% 83,0$ oranında başarılı sonuç elde edilmiştir. Literatürdeki diğer çalışmalarda da başarı oranı \%75 ile \%95 arasında değişmektedir (9-11).

Sondalama işlemi DNLKT' da standart terapötik bir yöntemdir. Ancak sondalama işleminin zamanlaması, kaç yaşına kadar etkili olabileceği yönündeki tartışmalar günümüzde halen devam etmektedir. Uzamış inflamasyon süresinin tıkanıklı̆ın olduğu bölgede fibrozisi artırarak tedavi başarısını düşürebileceği bildirilmiştir (12). Yani sondalamanın geciktirilmesi ile tedavi başarısının azalacağı, bu nedenle sondalamanın 3 yaş altındaki hastalara uygulanmasının uygun olacağı düşünülmüştür (9-11).

Mannor ve ark. yaptıkları çalışmalarında ilk 12 aylık bebeklerde sondalama ile $\% 92$ oranında başarı elde edebi- 
lirken, bu oran 24 ayda $\% 88,36$ ayda $\% 79,48$ ayda $\% 70$ ve 60 ayda ise \%41' e kadar düşmektedir (13). Stager ve ark. 2369 hastaya uyguladıkları çalışmalarında ilk 6 ayda sonda uygulamasıyla \%95 başarı, 7-12 ay arasında $\% 88,5$ başarılı sonuç elde ederken, 13 aydan sonra sonda uygulamasıyla $\% 86,5$ başarılı sonuç bildirmişlerdir (14). Okumuş ve ark. yaptıkları çalışmalarında 12-24 aylık hastalarda sonda uygulaması ile \%81,66, 25-36 aylık hastalarda \%56 oranında başarı sağlandığını belirtmişlerdir (15). Demirci sonda uygulaması ile $0-6$ ay arası hastalarda $\% 100,6-12$ ay arasında $\% 80,12$ aydan büyüklerde ise $\% 53$ başarı oranı bildirmiştir (16).

Tüm alt yaş gruplarında yaptığımız sondalama işleminde en başarılı sonuçların ilk 1 yaş altındaki grupta olduğunu gördük (\%100). Bu gruptaki başarı oranlarının literatürde de \%92-100 arasında yüksek oranda bulunduğu tespit edilmiştir.

Literatürde bazı çalışmalar sonda uygulamasında başarının artan yaş ile azaldığını bildirmekle beraber, farklı çalışmalarda yaşın artması ile sonda uygulamasının başarısının değişmediği gösterilmiştir. Mesala Robb yaptığı çalışmada hastaları yaşlara göre 4 gruba ayırmış ve 1214 ay grubunda \%89, 15-17 ay grubunda \%97, 18-23 ay grubunda \%91, 24-35 ay grubunda \%96, 36 ay ve üstü grupta \%93 oranında başarıya ulaşmıştır. Yaşla başarı oranları arasında istatistiksel anlamlı bir fark bulamamış ve daha önce herhangi bir nedenle tedavi uygulanmamış hastalarda 4-5 yaşlarında dahi başarılı olabileceğini savunmuştur (11). Bu sonuçlarla uyumlu olarak Zwaan bir yaş altındaki hastalarda sondalama başarı oranını $\% 96$ bildirirken, 1-2 yaş arasında $\% 87,2$ yaş üzerinde ise $\% 92$ olarak tespit etmiş ve bir yaş üstündeki olgular ile iki yaş üstündeki olguların sondalama sonuçlarının anlamlı bir farklılık göstermediğini bildirmiş̧tir (17).

Sturrock ve ark. sondalama uyguladıkları 156 hastanın 413 yıl takibi sonrası \%30' unda epifora ve sulanma şikayetlerinin hafifleyerek devam ettiğini gözlemiştir. Bu tür hastalarda başka bir girişimde bulunmaktansa bir süre beklemenin uygun olacağını, semptomlarda azalmanın gözlenebileceğini, bu durumunun çocuğun gelişimi sırasında lakrimal sistemdeki pasajın çapının artması ve akıma olan direncin azalması ile açıklanabileceğini belirtmişlerdir (18).

Kushner ve ark. ise DNLK 'da tıkanıkık tiplerini inceledikleri çalışmalarında \%53 basit (membranöz) tıkanıklık olduğunu ve bu grupta başarının \%100 'e ulaştı̆̆ını, \%48' inin ise komplike tıkanıklık olduğunu ancak bu hastalarda \%36 başarılı sonuç elde ettiklerini bildirmişlerdir. Çalışmalarında basit tıkanıklıklarda sondalama başarısının daha fazla olduğu, komplike tıkanıklıkların ileri yaşta daha sık görülebileceği, sondalamanın ileri yaş grubundaki basit tıkanıklıklarda da etkili bir yöntem olduğu vurgulamıştır (19). Kashkouli ve ark. da 3 yaş ve üzeri sondalama uyguladıkları ancak başarısız olan çocukları incelediklerinde en önemli etkenin nazolakrimal kanalda komplike tıkanıklık olduğunu öngörmüştür (20). Paul ve ark. yaşla birlikte başarı oranının düşmesini, hafif tıkanıklıkların erken dönemde spontan açılmasına, ileri yaş grubunda ise ciddi tıkanıklıkların kümülatif olarak birikmesine bağlamışlardır (21).

Zilelioğlu ve ark. yaş, cinsiyet, epifora sıklığı ve lateralite ile sondalama başarısı arasında istatistiksel olarak anlamIı ilişki tespit etmemişler iken bizim çalışmamızda sondalama yaşı ile başarı arasında ilişki saptanmıştır (22).

Erdöl ve ark. yaptıkları çalışmada 13-24 ay arasında sondalama başarısını \%94, 25-48 ay arasında \%81 olarak bildirmişlerdir (23). Elibol ve ark. yayınladıkları çalışmada, 7-12 aylar arasında \%86, 1-2 yaş arasında \%100, 2 yaş üstünde ise $\% 21$ başarıı sonuç bildirmişlerdir ve 2 yaş altındaki hastalarla, 2 yaş üstündeki hastalar arasındaki başarı farkının anlamlı olduğunu saptamışlardır (24). Sturrock ve ark. çalışmalarında 12 aydan küçük hastalarda sonda girişiminde $\% 87$ başarılı sonuç elde edilirken, 2 yaşından büyük olgularda başarı oranı $\% 43$ 'de kalmıştır (18). Bizim çalışmamızda ise 24 ay altında sonlama başarı yüzdesi \%86.7 iken, 24 ay üzerinde $\% 55.7$ bulunmuştur.

Sondalama işleminde yaşın 36 ayın üstünde olması, bilateral tıkanıklık, genişlemiş lakrimal kese, hidrostatik masaja cevapsızlık, membranöz olmayan tıkanıklıklar prognozu kötüleştiren, sondalama başarısını etkileyen risk faktörleridir $(6,11)$. Bizim çalışmamızda ilk sondalamada başarılı olamayan hastalar incelendiğinde önceden masaj verilmiş, kronik nazolakrimal kanal tıkanıkığı öyküsü mevcut olan hastalardan oluştuğu, en önemli etkenin gecikmiş yaş ve gecikmiş sondalama olduğu tespit edilmiştir.

Sondalama işlemi günümüzde DNLKT olan bebeklerde inhalasyon anestezisi altında uygulaması güvenilir ve etkili minimal invaziv bir yöntemdir. Yaşamın ilk bir yılında hidrostatik masaj ile hastayı izlemek, 1 yaşından sonra NLK tıkanıklığı olan hastalarda gecikmeden sondalama işlemini yapmak hasta için en uygun seçenek olacaktır. Sık enfeksiyon geçiren, mukoseli olan hastalara 1 yaşından önce sondalama önerilmektedir.

\section{Kaynaklar}

1. Calhoun JH. Problems of the lacrimal system in children. Pediatr Clin North Am. 1987;34(6):1457-65.

2. Young JD, MacEwen CJ. Managing congenital lacrimal obstruction in general practice. BMJ 1997;315(2):293-6.

3. MacEwen $C J$, Young JD. Epiphora during the first year of life. Eye 1991;5(5):596-600.

4. Kushner BJ. Congenital nasolacrimal system obstruction. Arch Ophthalmol 1982;100(4):597-600.

5. Casady JV. Dacryocystitis of infancy. Am J Ophthalmol 1948;31(7):773-780.

6. Takahashi Y, Kakizaki H, Chan WO, Selva D. Management of congenital nasolacrimal duct obstruction. Acta Ophthalmol 2010;88(5):506-513.

7. Broggi RJ. The treatment of congenital dacryostenosis. AMA 
Arch Ophthalmol 1959;61(1):30-36.

8. Baker JD. Treatment of congenital nasolacrimal system obstruction. J Pediatr Opththalmol Strabismus 1985;22(1):34-5.

9. Katowitz JA, Welsh MG. Timing of initial probing and irrigation in congenital nasolacrimal duct obstruction. Ophthalmology 1987;94(6):698-705.

10. Miller A.M., Chandler D.L., Repka M.X., Hoover D.L., Lee K.A., Melia M., Paul J.R., David I.S. Office probing for treatment of nasolacrimal duct obstruction in infants. J. Aapos. 2014;18(1):26-30.

11. Robb RM. Success rates of nasolacrimal duct probing at time intervals after 1 year of age. Ophthalmology 1998;105(7):130710.

12. Ffooks $\mathrm{OO}$. Dacryocystitis in infancy. $\mathrm{Br} \mathrm{J}$ Ophthalmol 1962;46(7):422-434.

13. Mannor GE, Rose GE, Frimpong-Ansah K, Ezra E: Factors affecting the success of nasolacrimal duct probing for congenital nasolacrimal duct obstruction. Am J Ophthalmol 1999;127(5):616-617.

14. Stager D, Baker JD, Frey T, Weakley DR, Birch EE. Office probing of congenital nasolacrimal duct obstruction. Ophthalmol Surg. 1992;23(7):482-484.

15. Okumuş S, Erbağcı İ, Güngör K, Bekir N. Doğumsal Nazolakrimal Kanal Tıkanıklığı Olan Hastalara Yaş Gruplarına Göre Uyguladığımız Tedavi Yöntemleri ve Sonuçlarımız. Türkiye Klinikleri J Ophthalmol. 2009;18(4):223-9.

16. Demirci KYF, Demirci H, Bilgin KL. Doğumsal nasolakrimal kanal tıkanıklı̆ıı tedavisinde lavaj-sonda. T oft Gaz 1995;25:365-368.

17. Zwaan J: Treatment of congenital nasolacrimal duct obstruction before and after the age of I year. Ophthalmic Surg Lasers 1997;28(11):932-936.

18. Sturrock SM, MacEwen CJ,Young JDH.Long term results after probing for congenital nasolacrimal duct obstruction.Br J Ophthalmol 1994;78(12):892-894.

19. Kushner BJ. The magement of nasolacrimal duct obstruction in children between 18 months and 4 years old. J AAPOS.1998;2(1):57-60.

20. Kashkouli $M B$, Beigi $B$ et al. Late and very late inital probing for congenital nasolacrimal duct obstruction: what is the cause of failure? Br J Ophthalmol 2003;87(9):1151-1153.

21. Paul TO, Shepherd R. Congenital nasolacrimal duct obstruction:natural history and the timing of optimal intervention. J Pediatr Strabismus 1994;31(6):362-7.

22. Zilelioglu G, Hosal M.B. The results of late probing in congenital nasolacrimal duct obstruction. Orbit 2007;26(1):1-3.

23. Erdöl H, İmamoğlu HI, Aslan MF. Dört yaşından küçük çocuklarda konjenital nazolakrimal kanal tıkanıklığının tedavisi. Türkiye Klinikleri J Oftalmoloji 1999;8(4):240-243.

24. Elibol O, Güler C, Topalkara A, Demircan S. Konjenital nazolakrimal kanal tıkanıkığı. Türkiye Klinikleri Oftalmoloji 1996;3(4):273-6. 